\title{
Benchmarking scientific performance by decomposing leadership of Cuban and Latin American institutions in Public Health
}

\author{
Zaida Chinchilla-Rodríguez ${ }^{1,4}$ - Grisel Zacca-González ${ }^{2}$. \\ Benjamín Vargas-Quesada ${ }^{3,4}$ • Félix de Moya-Anegón ${ }^{1,4}$
}

Received: 19 October 2015

(C) Akadémiai Kiadó, Budapest, Hungary 2016

\begin{abstract}
Comparative benchmarking with bibliometric indicators can be an aid in decision-making with regard to research management. This study aims to characterize scientific performance in a domain (Public Health) by the institutions of a country (Cuba), taking as reference world output and regional output (other Latin American centers) during the period 2003-2012. A new approach is used here to assess to what extent the leadership of a specific institution can change its citation impact. Cuba was found to have a high level of specialization and scientific leadership that does not match the low international visibility of Cuban institutions. This leading output appears mainly in non-collaborative papers, in national journals; publication in English is very scarce and the rate of international collaboration is very low. The Instituto de Medicina Tropical Pedro Kouri stands out, alone, as a national reference. Meanwhile, at the regional level, Latin American institutions deserving mention for their high autonomy in normalized citation would include Universidad de Buenos Aires (ARG), Universidade Federal de Pelotas (BRA), Consejo Nacional de Investigaciones Científicas y Técnicas (ARG), Instituto Oswaldo Cruz (BRA) and the Centro de Pesquisas Rene Rachou (BRA). We identify a crucial aspect that can give rise to misinterpretations of data: a high share of leadership cannot be considered positive for institutions when it is mainly associated with a high proportion of non-collaborative papers and a very low level of performance. Because leadership might be questionable in some cases, we propose future studies to ensure a better interpretation of findings.
\end{abstract}

Zaida Chinchilla-Rodríguez

zaida.chinchilla@csic.es

1 CSIC, Institute of Public Goods and Policies, Albasanz 26-28, 28037 Madrid, Spain

2 Department of Teaching and Research, National Medical Sciences Information Centre-Infomed, Calle 23 No. 654 entre D y E, Vedado, CP 10400 Havana, Cuba

3 Department of Information and Communication, University of Granada, Campus de Cartuja s/n, 18071 Granada, Spain

$4 \quad$ SCImago Research Group, Madrid, Spain 
Keywords Public Health · Latin America - Cuba - Scientific collaboration · Normalized citation · Leadership

Mathematics Subject Classification 94 Information and communication · Circuit

JEL Classification D8 Information · Knowledge · Uncertainty

\section{Introduction}

Publication in scientific journals broadly reflects the results of institutional research activity. The evaluation of research efforts that materialize as scientific articles provides information that is useful for decision-makers in the realms of higher education (Huang et al. 2006) as well as among research units themselves. By assessing the productive activity of their institutions and establishing long-term goals, the pertinent agents or authorities may better allocate limited resources (Huang 2012) and formulate more appropriate research policies.

Peer review (Bornmann 2011; Hendrix 2008) and bibliometric indicators (Huang 2012) are the two key elements involved in such assessment processes. Yet one runs into serious limitations, especially in terms of time and budget, when a great number of units must be evaluated. Appraising the returns of a national research system based on these methods can thus be a difficult enterprise (Abramo et al. 2013). Quantitative data, for instance based on bibliometric indicators, may serve to derive a panoramic, international view of research results (Bornmann et al. 2014b).

At present, bibliometrics is the foremost tool in applications meant to evaluate institutions, particularly in the natural sciences and life sciences (Bornmann 2013). It is used by academic institutions to evaluate the productivity and quality of their research efforts (Hendrix 2008). The most commonly used bibliometric indicators are the number of publications, and the number of times articles are cited (Bornmann et al. 2012; Bornmann 2013). These data allow evaluators to gauge the intensity and impact of research in a given institution (Vieira and Gomes 2010).

Whether on a national level or an institutional one, a great volume of output is associated with a high impact of citation. In other words, the concentration of research in an institution is positively related with a superior performance (Moed et al. 2011). However, it may be that indicators based on the total number of documents do not adequately measure scientific progress (Rodríguez-Navarro 2012). For this reason, bibliometric tools have evolved to measure the impact of citations received by the publications of an institution, to compare the relative impact attained by other publications of the same year, the same type of document, and the same subject matter (Rehn et al. 2007). A second level of normalization of the impact of citation has been introduced-percentiles. The higher the percentile for a publication, the more citations it has received compared to the reference set of publications in the same field and year (Calero-Medina et al. 2008; Bornmann and Mutz 2011; Bornmann 2013; Bornmann and Moya Anegón 2014).

All these means of measuring scientific activity make it possible to perform comparative benchmarking. As bibliometric data are available for the entire world, institutions can be compared for the same period of time and a single subject area, given adequate normalization (Bornmann et al. 2014b); this reveals whether they are "above" or "below" 
expectations (Bornmann and Moya Anegón 2014). Citation-based normalized indicators are valid for domain study and comparative analysis at this level (Glänzel et al. 2009).

Studies contributing to scientific progress in a field rely heavily on the highly cited articles (Bornmann et al. 2010). Two indicators are currently used to reflect the most substantial contributions made: the percentage of scientific excellence and the ratio of documents published in the most influential journals. The excellence indicator shows the percentage of papers published by an institution belonging to the top $10 \%$ papers in terms of numbers of citations, normalized for the same field of publications and the same publication year (Bornmann et al. 2012). The percentage of excellence is considered one of the most important indicators for the comparison of institutions, ordered according to their scientific productivity. It provides information about the long-term success of the publications of an institution. Meanwhile, the ratio of documents that a public institution publishes in the most influential academic journals in a given area or discipline, i.e. in the first quartile (top $25 \%$ ), describes an early stage in this process, that is, the capacity of an institution to publish in high impact journals (Rodríguez-Navarro 2012; Bornmann et al. 2014b). A study by Huang (2012) confirmed the validity of the $h$ index in the evaluation of research endeavors in the university setting; posterior variants of this indicator, such as the ${ }^{\mathrm{n}} h_{3}$, introduce a correction factor for the dependence on the size of the institutions (Vieira and Gomes 2010).

Another interesting approach is that of the "research guarantor", which can serve to question how the consideration of leadership may change the position of specific countries or institutions within rankings based on citation impact. The method is simply based on identifying the corresponding author by the percentage of documents produced by a country or institution in which the main author is affiliated to a national institution of the given country. It has thus far been applied at the country level, comparing distributions of normalized citation impact corresponding to the different types of output (total and excellent output based on all co-authors or the research guarantor only) (Moya-Anegón et al. 2013) and quantifying the gain in impact that occurs in scientific collaboration (Guerrero et al. 2013).

This growing interest in the comparative assessment of institutions has led to a series of rankings, fundamentally of universities. In 2003, Shanghai Jiao Tong University published The Academic Ranking of World Universities (ARWU) (Institute of Higher Education, Shanghai Jiao Tong University 2013). Since, about 10 highly relevant international rankings have been developed (Hazelkorn 2013). The U-Multirank of the European Union uses a multidimensional focus to compare the research, teaching, transfer of knowledge and international orientation of universities (CHE Centre for Higher Education 2014); the Webometrics rankings takes into account the characteristics of published web contents and appraises the institution in the social context of universities worldwide (Aguillo et al. 2010); and the Leiden ranking measures the scientific performance of the main 500 universities in the world (Centre for Science and Technology Studies, CWTS, 2014).

The SCImago Research Group publishes, annually, the SCImago Institutions Rankings (SIR) (2014), based on the Scopus database. These comprehensive reports actually include a number of bibliometric indicators that can be used to characterize the results of an institutiońs research effort. The Ibero-American SIR takes in all the institutions of higher education in Ibero-American countries producing at least one document, whereas the Global SIR covers all the institutions in any country publishing at least 100 documents in the last year of the five-year period. Both are founded on bibliometric indicators of output, leadership, excellence, normalized impact, specialization, and international collaboration (SCImago Institutions Rankings 2014). 
The present study uses some indicators directly published by the SIR to assess the scientific output of Cuban institutions in the area of Public Health, in the Latin American institutional context. Other indicators and representations have been included so as to complement and enrich the methodology of a series of studies intended to characterize the research capacity in Public Health within Latin America and in Cuba in particular (ZaccaGonzález et al. 2014a, b; Chinchilla-Rodríguez et al. 2015a, b, c; Zacca-González et al. 2015). One noteworthy methodological aspect is the decomposition of the leadership indicator (non-collaborative and co-authored papers: domestic and international) combined with the normalized citation impact. We compare the normalized citation of all output against the normalized citation of leadership output. The goal is to find out to what extent the institutions depend on collaboration to heighten research performance in terms of citations, thus refining the notion of leadership. To the best of our knowledge this is the first study adopting this approach at the institutional level.

Another important aim is to contribute complementary information of value in the framework of the essential public health functions (EPHF), specifically number 10, referring to research in public health. The EPHF are processes and movements that provide for a better management of public health. The strategic importance of the essential functions (such as vigilance, monitoring and promotion of health) resides in the generation by the health system of an effective, efficient and quality response to collective interests in the area of health. The Pan American Health Organization/World Health Organization (PAHO/WHO 2002), defines the EPHF as the indispensable set of actions, under the primary responsibility of the state, to improve, promote, protect, and restore the health of the population through collective action. EPHF 10 includes research aimed at increasing knowledge to support decision-making at various levels; the implementation of innovative solutions in public health whose impact can be measured and assessed; and the intra- and inter-sectoral partnerships with research centers and academic institutions. In short, what is appraised is development of a public health research agenda and the institutional research capacity, and technical assistance at subnational levels for research in public health. Our results may shed light on some of these points.

\section{Main objective and research questions}

To characterize the scientific performance in Public Health of Cuban institutions as opposed to the rest of the Latin American institutions, in terms of output, specialization, impact, excellence, leadership and collaboration, in view of the scientific journals registered in the Scopus database for the period 2003-2012.

Along the way, we respond to the following questions: Which institutions show the greatest output in Public Health, and which are most highly specialized? Which institutions achieve greater impact and excellence with their scientific output? Which institutions have a greater degree of scientific collaboration? Which ones are more autonomous or more dependent upon collaboration in their scientific performance? In what language do they publish? What position in the SIR rankings do these institutions occupy? What similarities and differences are seen in their scientific activity when compared with the world average and the main Latin American institutions? How might the bibliometric indicators of institutions complement the evaluation of Function 10? 


\section{Materials and methods}

The bibliometric information for the period 2003-2012 was partially extracted from the SCImago Institutions Rankings (SIR 2014), based on Scopus data, in the category Public Health, Environmental and Occupational Health, which is a subset of the area of Medicine.

The SIR uses a complete count method to attribute the Scopus articles to their respective institutions. Normalization entails a thorough process of identification and disambiguation of institutions, in view of the institutional affiliation of each author as defined in the field Affiliation of Scopus, using a mixed system (manual and automatic) to group the multiple variants of institutional affiliation of an institution under a single identification (SCImago Institutions Rankings 2014). For the purposes of this study, only institutions having at least 10 documents in Public Health over the period 2003-2012 were analyzed. This gave 14 (out of a total of 142 Cuban institutions publishing at least one document in the journals indexed by Scopus). To contextualize the analysis, these 14 were compared with the 40 Latin American institutions showing the greatest overall volume of publication in Public Health, amounting to approximately $10 \%$ of the total number of Latin-American institutions with at least 10 documents in Public Health.

The bibliometric indicators used were:

- Number of documents (Ndoc) (total output): the number of documents published in indexed academic/scientific journals, in the Scopus category Public Health, Environmental and Occupational Health.

- Leadership (\% Lead) (leading output): Percentage of output by an institution in which the main author ("corresponding author") belongs to the institution (Moya-Anegón et al. 2013). At the institutional level, this indicator was split into three more categories: non-collaborative papers, leading papers in domestic collaboration, and leading ones in international collaboration.

- Collaboration types (percentages): (a) No-collaboration (\% NonC): papers published by one single institution regardless of the number of authors that signed the manuscript; (b) Total collaboration: total of co-authored papers; (c) Collaboration with leadership: total leading co-authored papers; (d) National Collaboration (\%NatC): co-authored papers with institutions located in the same country; (e) National Collaboration with Leadership: leading co-authored papers in national collaboration; (f) International collaboration (\% IC): co-authored papers with foreign institutions; and (g) International collaboration with leadership (\%IC_L): internationally co-authored papers with leadership including those papers published in national and international collaboration.

- Citation per document (cpd): Average number of citations received by the whole scientific production of an aggregate within the period of study.

- $\%$ of documents cited (\%CitDoc): Percentage of documents of an institution that receive at least one citation.

- Publications in national journals (\% Ndoc national journals): percentage of documents that were published in domestic journals.

- Publications in the most cited journals (\%Q1): Percentage of documents published in the journals that are in the first quartile $(25 \%)$ of their respective categories, according to the order derived from the SCImago Journal Rank (SJR) indicator.

- Normalized citation impact (NI): the relative number of citations received by each institution compared with the world average citation per document of works sharing the same document type, year and category. This was calculated using the methodology 
"Item oriented field normalized citation score average", where the normalization of the citation values is applied to the individual article (Rehn et al. 2007). The values show the relationships between the mean scientific impact of an institution and the world mean, with a score of 1 . An NI of 0.8 therefore means that the institution is cited $20 \%$ less than the world average; a value of 1.3 would mean it is cited $30 \%$ more than the world average.

- Normalized citation impact with Leadership (NIL): the relative number of citations received by each institution acting as corresponding author compared with the world average citation per document sharing the same document type, year and category (Moya-Anegón et al. 2013).

- Benefit Rate of Collaboration in Normalized Citation Impact (BRCNI): the percentage difference between the Normalized Citation Impact of all output (NI) and the Normalized Citation Impact of leading output (NIL). This indicator allows us to determine the benefit on impact of co-authored papers at a national or international level. When the value is very low (less than $25 \%$ ) or even negative, it signals a scientifically well-developed institution whose NI of total output adequately reflects their scientific performance. If the difference between the two indicators is very high (above $40 \%$ ), we are dealing with scientifically developing institutions. We can therefore say that this measure of profit based on scientific leadership can be used to discern institutions having scientific autonomy (Moya-Anegón et al. 2013). The threshold can vary from one domain to another, but the rule of thumb is: the lesser the benefit rate, the better developed and more autonomous the institution.

- Excellence rate (\% Exc): Percentage of scientific output by an institution that is included within the set of the $10 \%$ of the most cited papers in that category. It is a measure of the high quality output of research institutions.

- Excellence with leadership (\% EwL): Percentage of documents of excellence from the institution considered the main contributor.

- Activity Index (AI): This appraises the relative effort dedicated by an institution to a specific domain of knowledge, thus reflecting the comparative specialization in a subject area, in this case, Public Health. To facilitate comparison among institutions, the AI was transformed so that it would take on values between -1 and 1 , where 0 represents the position with respect to the world in the category of Public Health; values over 0 indicate a greater specialization in scientific output than the world average (Glänzel 2000).

$$
\mathrm{AI}=\left[\left(\operatorname{Ndoc}_{\mathrm{PH}(\text { institution })} / \mathrm{Ndoc}_{\text {total(institution })}\right)\right] /\left[\left(\mathrm{Ndoc}_{\mathrm{PH}(\text { world })} / \mathrm{Ndoc}_{(\text {world })}\right)\right]
$$

The degree of specialization was classified according to the scale proposed by the Karolinska Institutet: $\mathrm{AI} \geq 0.8$ very high level of specialization, $\mathrm{AI} \geq 0.6$ to $<0.8$ high level, $\mathrm{AI} \geq 0.4$ to $<0.6$ medium level, $\mathrm{AI} \geq 0.2$ to $<0.4$ low level, and $<0.2$ a very low level of specialization (Rehn et al. 2007).

\section{Results}

\section{Analysis of Cuban institutions}

During the period 2003-2012, Latin America published 18,990 documents in the category Public Health, Environmental and Occupational Health. This figure represents $2.45 \%$ of 
the total output of the region and $6.11 \%$ of world output in this category. While at world level, a total of 310,789 documents were indexed in Scopus database representing $1.66 \%$ of all documents. Cuba published 824 documents. Out of this total, $94 \%$ of works originated in a core of 14 institutions, each publishing more than 10 documents in the category (Table 1).

The Instituto Nacional de Higiene y Epidemiología (INHEM) heads the list of Public Health-related institutions with substantial output, producing $21.72 \%$ of the total number of Cuba's articles on Public Health. Closely following this rather prolific institution, and both showing over $16 \%$ of the total output, are the Instituto de Medicina Tropical Pedro Kouri (IPK) and Escuela Nacional de Salud Pública (ENSAP). Meanwhile, the Instituto Superior de Ciencias Médicas de La Habana (ISCM-H), which governs a number of University schools, also makes an important contribution to Public Health (over $10 \%$ ). The University of Havana (UH), the only institution on the list that does not belong to the National Health System of Cuba, contributed over $5 \%$ of the total. Just under $5 \%$ came from the Instituto Nacional de Endocrinología (INE) and the Ministry of Public Health (MINSAP). The only hospital making the list, Hospital Clínico Quirúrgico Hermanos Ameijeiras (HCQ-HA), produced $2.67 \%$ of the documents. Further institutions publishing in journals indexed under Public Health are ones specializing in oncology, nutrition, neurology, angiology and cardiology (Table 1).

In order to examine the priority that these institutions give to Public Health, we used the Activity Index. According to the scale introduced by the Karolinska Institutet, the centers showing a very high level of specialization would be INHEM (0.97), Centro Provincial de Higiene y Epidemiología de Ciudad de La Habana -CPHE-CH (0.94), ENSAP (0.93), the institutes of EndocrinologyINE (0.92), Angiolology-INACV (0.88) and Nutrition-INHA $(0,81)$, Ministerio de Salud Pública La Habana-MINSAP (0.89) and IPK (0.85). A high level of specialization is seen for the Instituto Nacional de Oncología y RadiobiologíaINOR (0.76), the ISCM-H (0.72), Centro Internacional de Restauración NeurológicaCIREM (0.74) and the Instituto de Cardiología y Cirugía Cardiovascular-ICCC (0.64). Showing a medium degree of specialization is HCQ-HA (0.51); finally, the UH has a very low level (0.16).

In some institutions there is a marked difference between the percentage of coauthored papers and international collaboration. This disparity is greater among: ICCC, INE, CPHE$\mathrm{CH}$, and INACV. The difference means that these institutions have more domestic than international collaboration. As far as international collaboration is concerned (IC), the data indicate that IPK and UH have the most foreign participation in research results, followed by CPHE-H, INOR and INHEM (around $20 \%$ involving co-authors from other countries). The level of collaboration of the other Cuban institutions is lower than the national proportion $(20 \%)$, the regional figure (32\%) and the world figure (29\%). The ICCC is the extreme case, having no publication involving collaboration from abroad and exclusively working with domestic institutions.

Yet this scanty level of collaboration is accompanied by a high percentage of leadership. Indeed, Cuban leadership is much higher than the regional and world standards, where on the average institutions lead under half their output. CIREN was the institution having more authors (regardless of origin) involved in their publications, in contrast to INOR and IPK (38 and $58 \%$ ). When the leadership is decomposed into non-collaboration papers and collaborative papers with leadership, however, the fact is that most Cuban leadership is based on non-collaborative efforts. CIREN and HCQ-HA have the highest rates of noncollaborative papers. These centers only lead respectively 9 and $12 \%$ of their output involving some type of collaboration (domestic or international). Just $5 \%$ of CIREN 


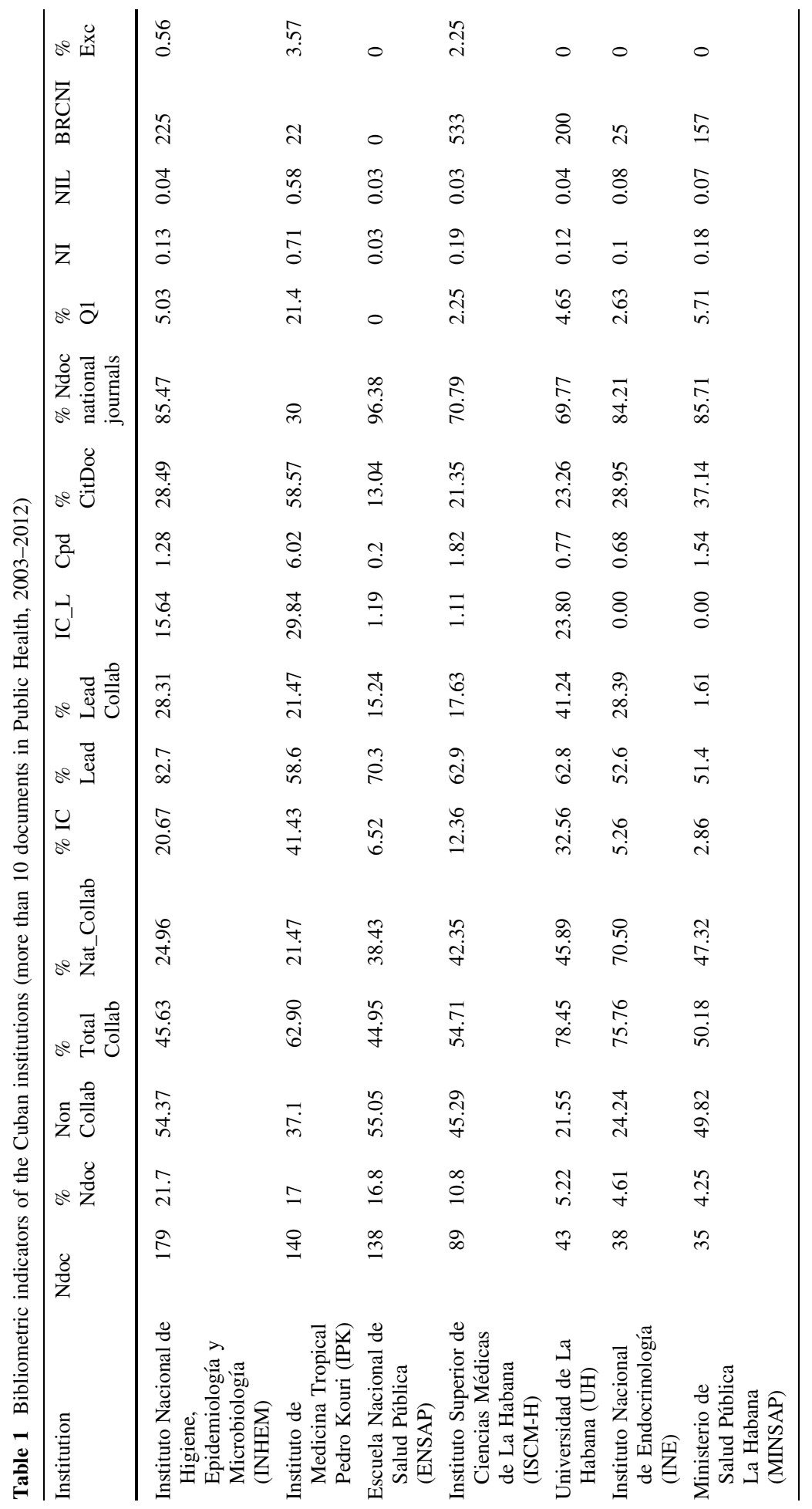




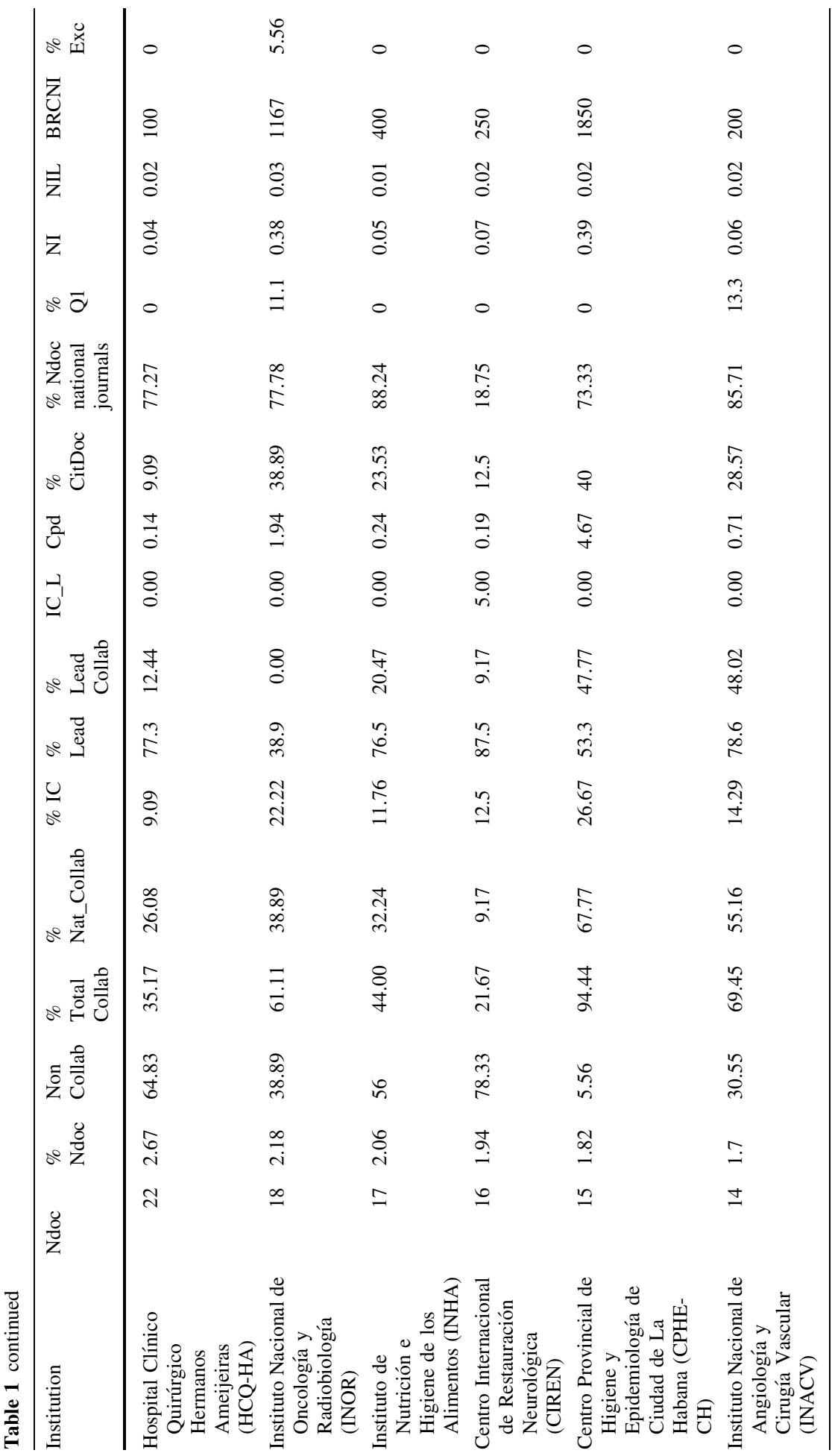




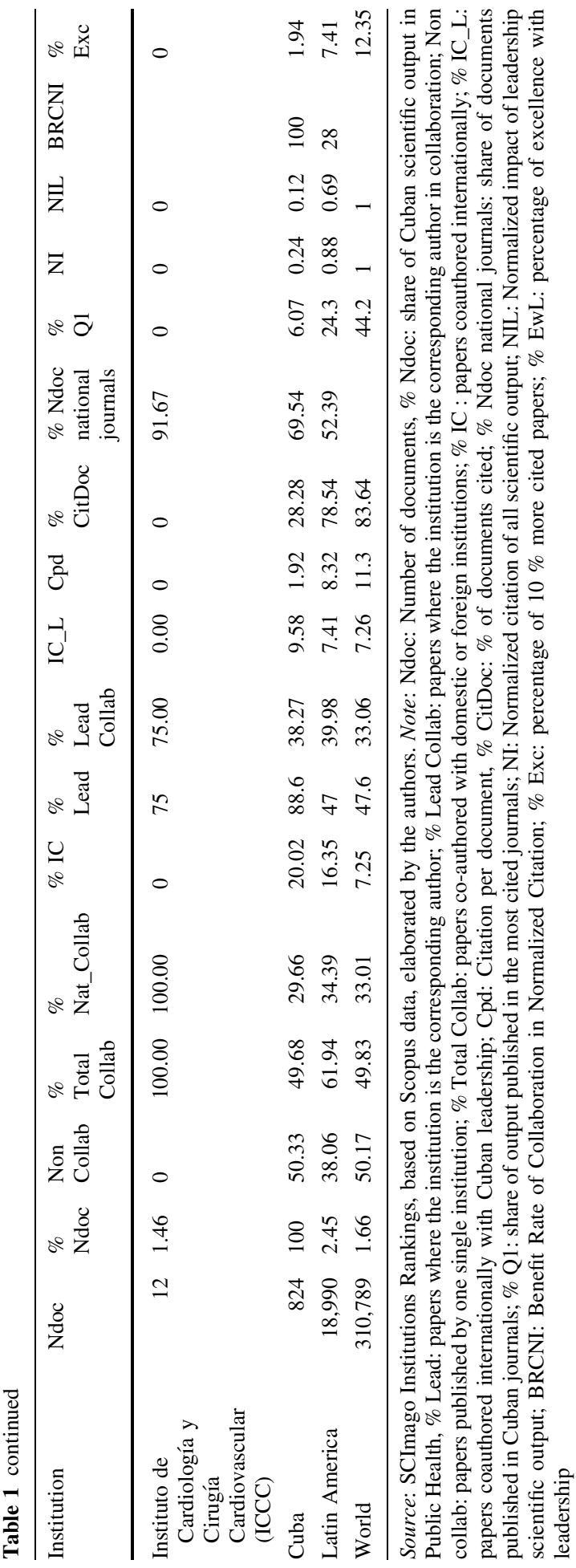


output is published in international collaboration, and the other $4.17 \%$ in domestic collaboration. HCQ-HA only leads when in collaboration with other Cuban institutions. Such domestic leadership in the total absence of international collaboration is likewise seen for the ICCC, CPHE-CH, INE, INACV, INOR, MINSAP and INHA. In contrast, the institutions having the highest rates of leadership in international collaboration are the IPK, UH and INHEM (column IC_L).

What about scientific performance? None of the Cuban institutions analyzed reach the world mean average for citation. The only institution close to the world mean for impact was the IPK (with $29 \%$ less than the mean). Most were cited far below ( $80 \%$ less) than the "peer" work of the same type, period and subject matter. When the values of normalized citation of all scientific output (NI) are compared to the ones of leadership output (NIL), the differences and the benefit rate of collaboration (BRCNI) are enormous, especially for CPHE-CH and INOR. This means that Cuban institutions gaining the most in citation when they collaborate with other institutions acting as leaders. In sum, collaboration is the key to scientific performance while leadership hardly contributes to visibility-except in the case of IPK, where the difference is not great, and its normalized citation is substantial compared to the rest of the Cuban institutions.

A composite analysis - of degree of specialization (Activity Index), normalized impact and volume of output - reveals the outstanding institution overall to be IPK (Fig. 1). The results harvested by INOR are also noteworthy. Then, there is a group of institutions with similar output and specialization, yet low impact: INHEM, ENSAP and ISCM-H.

Regardless the origin of citations, when the international repercussion of an institution is measured by the percentage of cited documents (\% DocCit), the IPK again reaps the best results, as over $50 \%$ of its articles are cited; followed by the CPHE-H (40\%), and INOR, INHEM and the Instituto de Endocrinología, these three around $28 \%$. The HCQ-HA received citations for less than $10 \%$ of its articles, while the work of the ICCC went noncited, despite the fact that all its production is published with the collaboration of other

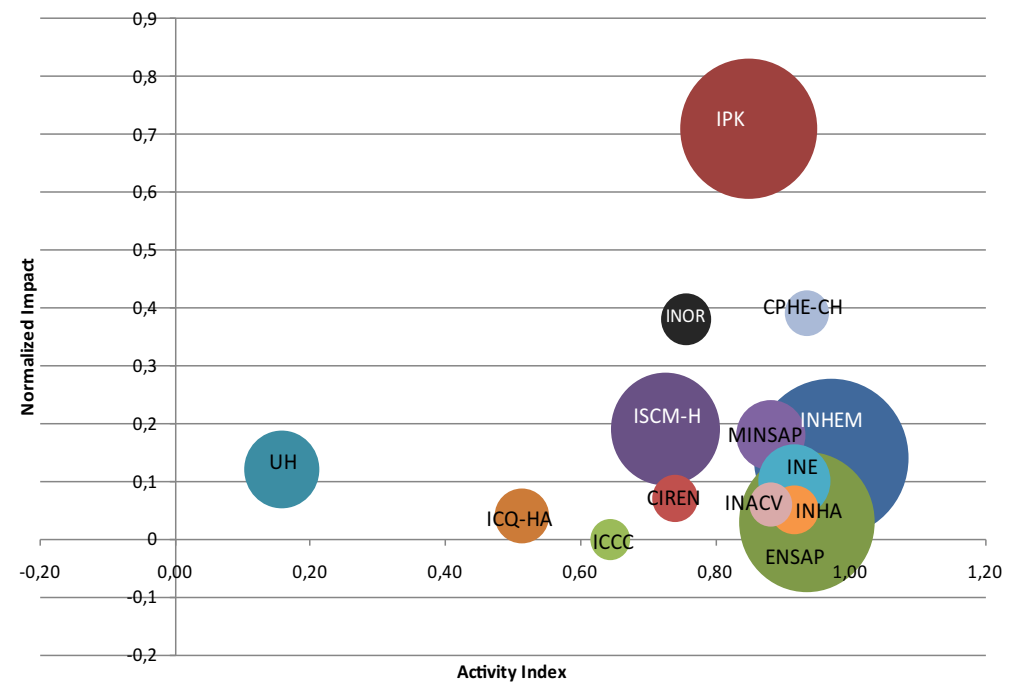

Fig. 1 Activity Index, normalized impact and output of Cuban institutions with at least 10 documents in Public Health, 2003-2012. Source: SCImago Institutions Rankings, based on Scopus data elaborated by the authors 
Cuban institutions. Again, this indicator is well below the Latin American average, not to mention the world average, for both Cuba as a whole and its individual institutions: roughly $78 \%$ of Latin American output in Public Health is cited, and the figure is $83 \%$ on the worldwide level (Table 1). The IPK attained the highest citation per document; the Centro Provincial de Higiene y Epidemiologia de Ciudad de La Habana has a cpd just over 4, and INHEM, ISCM-H, MINSAP, and INOR do not reach $2 \mathrm{cpd}$. The remainder had none. These values are far from the regional and international parameters of 8 and $11 \mathrm{cpd}$, respectively.

The levels of output in the journals of the first quartile are very low indeed (\%Q1), and even poorer results are seen for work in of the most cited documents (excellence). Output with leadership and excellence, the most cited $10 \%(\mathrm{EwL})$, is non-existent. The IPK clearly shows the best results, publishing in prestigious journals (30 documents, $21.4 \%$ ) while achieving excellence ( 5 papers, $3.6 \%$ ); among the excellent documents, only one was actually led by this institution. Another institution deserving mention here is INOR, in spite of their low proportions of excellence and leadership. Among the institutions with the most output, ENSAP nonetheless did not manage to publish any article in the subgroups of top quality (Table 1).

The percentage of documents published in national journals (Revista Cubana de Salud Pública and Revista Cubana de Higiene y Epidemiología) is high for nearly all the institutions (Table 1). While CIREN and IPK are the ones publishing the least in the national journals, ENSAP and ICCC publish the vast majority of their articles in these 4th quartile journals.

The language distribution of the Cuban Public Health publications is displayed in Table 2. For all the institutions studied, the mother tongue (Spanish) prevailed, and it was actually the language of publication for $100 \%$ of the papers from CIREN and ICCC.

Table 2 Percentage of documents and citation per document according to language of publication, for the Cuban institutions with at least 10 documents in Public Health

\begin{tabular}{|c|c|c|c|c|c|c|c|c|}
\hline \multirow[t]{2}{*}{ Institution } & \multicolumn{2}{|l|}{ Spanish } & \multicolumn{2}{|l|}{ English } & \multicolumn{2}{|c|}{ Portuguese } & \multirow[t]{2}{*}{ Overlap } & \multirow{2}{*}{$\begin{array}{l}\text { Cpd } \\
\text { English/Spanish }\end{array}$} \\
\hline & $\%$ Ndoc & Cpd & $\%$ Ndoc & Cpd & $\%$ Ndoc & Cpd & & \\
\hline INHEM & 91.06 & 0.64 & 42.46 & 1.7 & 0.56 & 1 & 34.08 & 2.66 \\
\hline IPK & 62.86 & 2.86 & 50.00 & 8.43 & 2.86 & 0.75 & 15.71 & 2.95 \\
\hline ENSAP & 99.28 & 0.2 & 31.88 & 0.05 & 0.72 & 0 & 31.88 & 0.25 \\
\hline ISCM-H & 88.76 & 0.42 & 43.82 & 3.31 & 0.00 & 0 & 32.58 & 7.88 \\
\hline UH & 86.05 & 0.27 & 25.58 & 2.09 & 4.65 & 1 & 16.28 & 7.74 \\
\hline INE & 92.12 & 0.63 & 36.84 & 1.07 & 2.63 & 2 & 31.58 & 1.70 \\
\hline MINSAP & 94.29 & 1.03 & 37.14 & 1.85 & 0 & 0 & 31.43 & 1.80 \\
\hline HCQ-HA & 95.45 & 0.14 & 31.82 & 0 & 0.00 & 0 & 27.27 & 0.00 \\
\hline INOR & 83.33 & 0.47 & 33.33 & 4.83 & 0.00 & 0 & 16.67 & 10.28 \\
\hline INHA & 94.12 & 0.16 & 29.40 & 5 & 0 & 0 & 23.53 & 26.32 \\
\hline CIREN & 100 & 0.19 & 6.25 & 0 & 0.00 & 0 & 6.25 & 0.00 \\
\hline CPHE-CH & 86.67 & 2.15 & 40.00 & 8 & 0 & 0 & 26.67 & 3.72 \\
\hline INACV & 92.86 & 0.69 & 21.43 & 0.67 & 0 & 0 & 14.29 & 0.97 \\
\hline ICCC & 100 & 0 & 50.00 & 0 & 0.00 & 0 & 50.00 & 0.00 \\
\hline
\end{tabular}

Scopus 2003-2012. Source: SCImago Institutions Rankings, based on Scopus data, elaborated by the authors 
Similarly high are the proportions found for ENSAP and HCQ-HA. The institutions that put out more articles in English are IPK and INHEM. Some of these institutions have a high percentage of multilingual publications. Such is the case of the ICCC, 6 of its 12 articles appearing in bilingual format, Spanish/English. For all the aggregates, publication in English means greater impact. The output in English from the INOR is cited 10 times more than the publications in Spanish.

\section{Comparative institutional analysis, Latin America}

Using the order by default given in the SIR, below we show the position occupied by the institutions in the rankings ordered by number of documents, for Cuba and Latin America, in Public Health (Table 3). The first two columns show the institutional ranking in the Cuban context and the last one in the context of Latin America. Altogether, the one occupying the best position in the ranking is INHEM. Although INHEM has the top spot on the list of Public Health in Cuba, it is not remarkable in the light of other Cuban institutions. Listing the Latin American institutions according to their output in Public Health places the first Cuban institution in position 33; ISCM-H and UH head the list of Cuban institutions in total output, but the former is better situated regarding Public Health. National institutes such as those of Endocrinology, INHA and ICCC occupy positions far down the list in all cases. The Centro Provincial de Higiene y Epidemiología de Ciudad de La Habana, of a provincial scope, has a noteworthy position within the realm of Cuban Public Health, but its scarce volume of total production leaves it near the bottom of the other listings.

Table 4 shows the 40 institutions of Latin America with the largest volume of scientific output in the field of Public Health. The only Cuban institution listed is INHEM. Some patterns of communication of Cuban institutions differ from the best practices reflected by Latin American institutional patterns; at the same time, they have in common a high

Table 3 Position of the Cuban institutions with more than 10 documents in Public Health, ordered according to their scientific output

\begin{tabular}{lccc}
\hline Institution & Public health Cuba & All Cuban institutions & Public health Latin America \\
\hline INHEM & 1 & 18 & 33 \\
IPK & 2 & 4 & 37 \\
ENSAP & 3 & 10 & 39 \\
ISCM-H & 4 & 2 & 63 \\
UH & 5 & 1 & 120 \\
INE & 6 & 44 & 140 \\
MINSAP & 7 & 37 & 151 \\
HCQ-HA & 8 & 6 & 213 \\
INOR & 9 & 22 & 253 \\
INHA & 10 & 54 & 264 \\
CIREN & 11 & 26 & 279 \\
CPHE-CH & 12 & 102 & 300 \\
INACV & 14 & 70 & 327 \\
ICCC & 15 & 20 & 360 \\
\hline
\end{tabular}

Scopus 2003-2012. Source: SCImago Institutions Rankings, from Scopus data, elaborated by the authors 


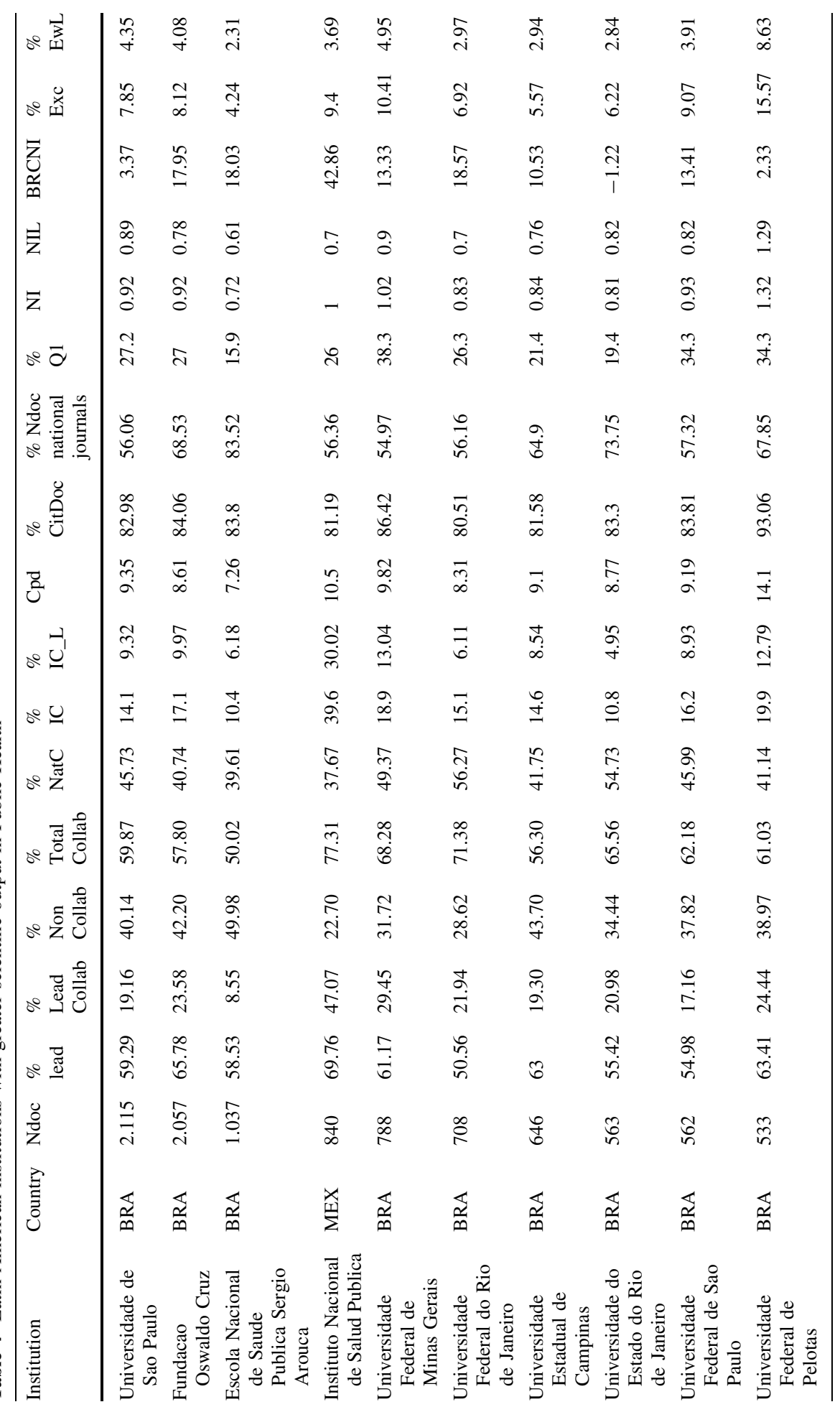




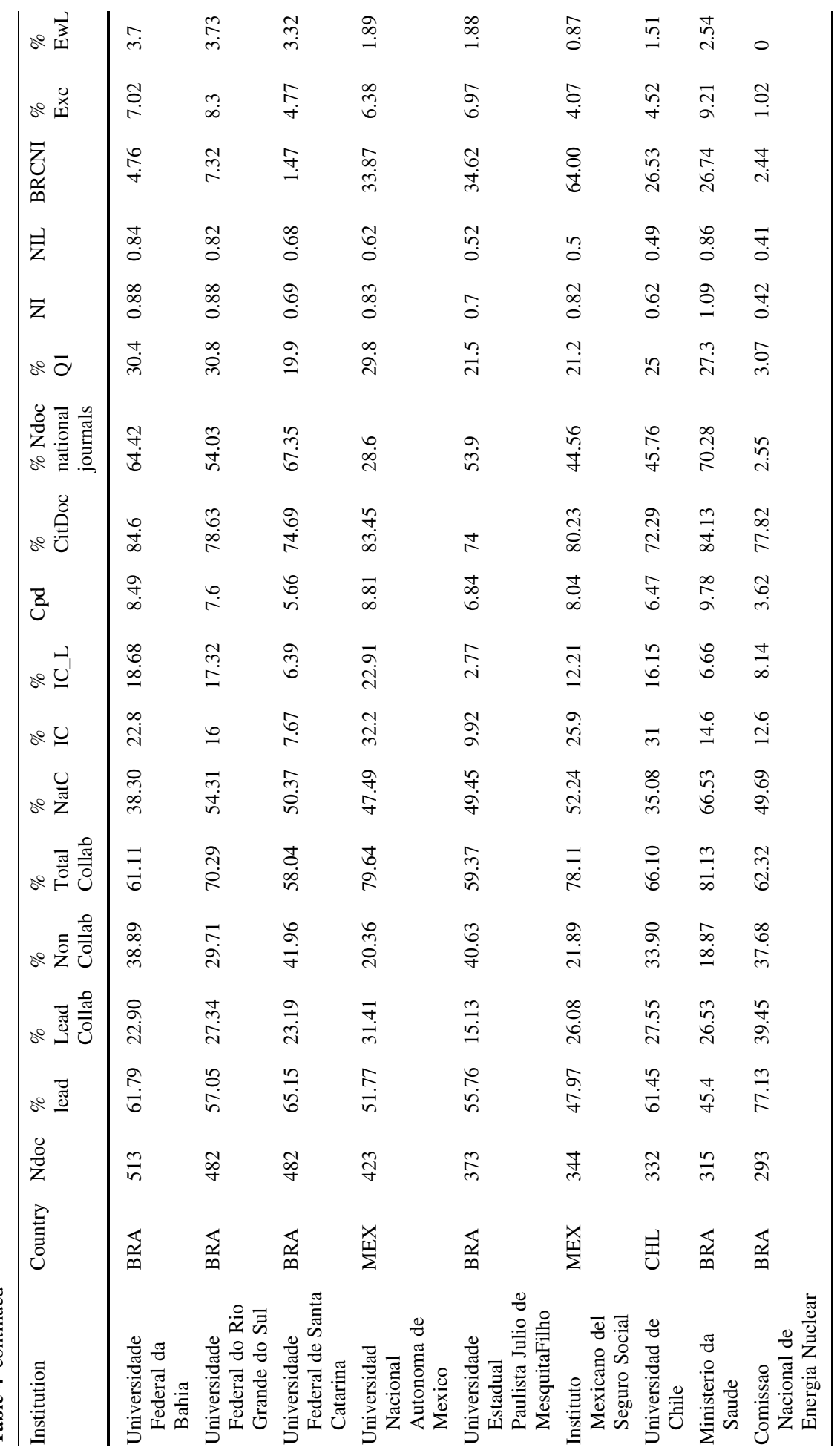




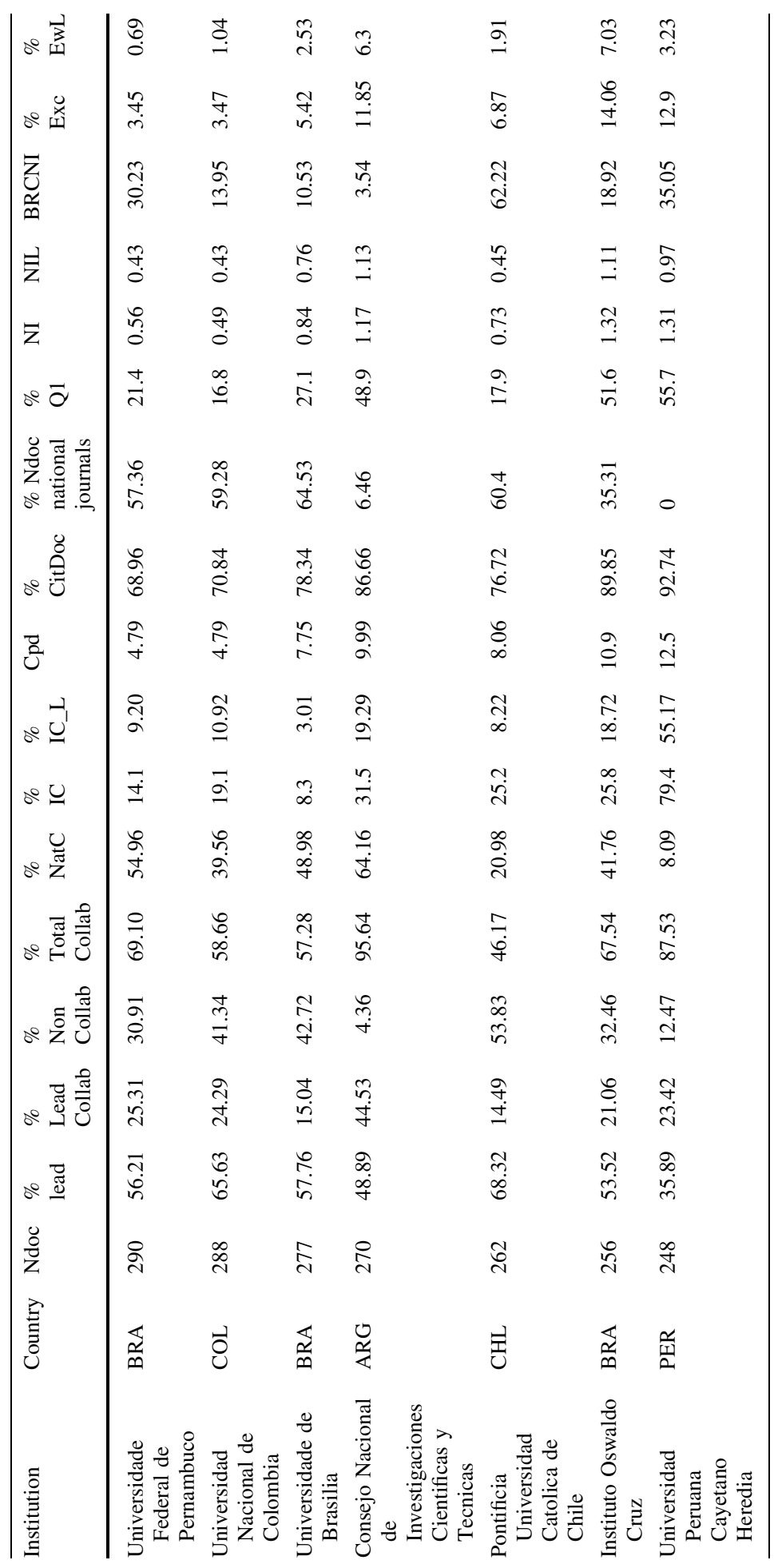




\begin{tabular}{|c|c|c|c|c|c|c|c|}
\hline ஃ。 & $\hat{m}$ & $\stackrel{\infty}{\stackrel{\infty}{\sim}} \stackrel{\infty}{\infty}$ & $\stackrel{\infty}{\stackrel{\infty}{\rightarrow}}$ & $\stackrel{g}{g}$ & i্ & o & $\stackrel{\tilde{i}}{i}$ \\
\hline ஷ盖 & $\stackrel{\infty}{\infty} \underset{\infty}{\infty}$ & 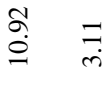 & iे & 呄 & $\cong$ & ?. & $\begin{array}{l}\stackrel{n}{+} \\
\stackrel{+}{+}\end{array}$ \\
\hline${ }_{\mathscr{u}}^{\bar{\Perp}}$ & $\stackrel{\leftrightarrow}{\stackrel{n}{\Xi}}$ & $\begin{array}{ll}\infty & \infty \\
i & 0 \\
i & n \\
1 & \end{array}$ & $\begin{array}{l}\infty \\
\infty \\
\infty \\
\infty\end{array}$ & 寺 & $\stackrel{f}{9}$ & $\begin{array}{l}8 \\
\text { dे } \\
\text { d }\end{array}$ & $\stackrel{\text { for }}{i}$ \\
\hline$\vec{z}$ & $\stackrel{\infty}{\infty}$ & $\stackrel{\infty}{-}$ & $\stackrel{\circ}{\circ}$ & 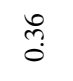 & $\stackrel{\infty}{\circ}$ & ta & $\stackrel{8}{0}$ \\
\hline $\bar{z}$ & - & $\stackrel{\leftrightarrow}{\rightarrow} \quad \stackrel{0}{\circ}$ & $\stackrel{i}{0}$ & $\stackrel{\vec{b}}{0}$ & 㔛 & $\stackrel{9}{0}$ & $\stackrel{\infty}{\stackrel{\infty}{0}}$ \\
\hline$\therefore \bar{\sigma}$ & $\stackrel{n}{\infty}$ & $\begin{array}{ll}\text { ma } \\
\text { gु }\end{array}$ & $\vec{i}$ & $\stackrel{\infty}{\dot{\Lambda}}$ & $\overrightarrow{\mathcal{q}}$ & 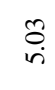 & $\stackrel{\infty}{\underset{I}{I}}$ \\
\hline 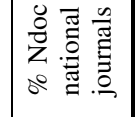 & $\frac{\tilde{\sigma}}{\dot{\sigma}}$ & 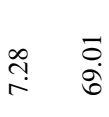 & $\circ$ & 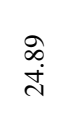 & त̂ & 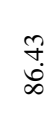 & 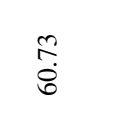 \\
\hline ○ & $\begin{array}{l}7 \\
\text { 7. } \\
2\end{array}$ & $\begin{array}{cc}0 \\
0 \\
0\end{array}$ & 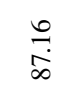 & $\underset{i}{i}$ & 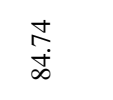 & है & 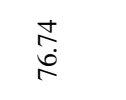 \\
\hline $\overrightarrow{0}$ & $\stackrel{t}{\stackrel{t}{r}}$ & $\begin{array}{l}\bar{n} \\
\text { s. }\end{array}$ & $\stackrel{n}{n}$ & $\begin{array}{l}\vec{\infty} \\
\dot{n}\end{array}$ & ñ & $\stackrel{g}{g}$ & $\stackrel{े}{\overrightarrow{0}}$ \\
\hline$\therefore$ & 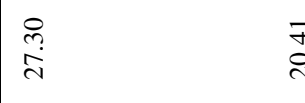 & 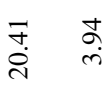 & 同 & $\begin{array}{l}\infty \\
\substack{\infty \\
\infty}\end{array}$ & 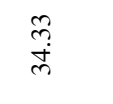 & $\begin{array}{l}\overrightarrow{\Phi_{i}} \\
\mathbb{I}\end{array}$ & 苘 \\
\hline$\therefore$ & 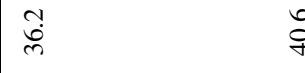 & 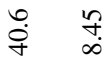 & iे & $\frac{n}{q}$ & $\begin{array}{l}0 \\
\text { ¿ై }\end{array}$ & $\begin{array}{l}n \\
\infty \\
\infty\end{array}$ & $\stackrel{\mathscr{n}}{n}$ \\
\hline ஃ. & $\begin{array}{l}0 \\
0 \\
0 \\
0\end{array}$ & $\begin{array}{ll}\vec{F} & i \\
\dot{f} & i \\
m & \infty \\
n\end{array}$ & $\begin{array}{c}\infty \\
\substack{\infty \\
i}\end{array}$ & $\begin{array}{l}\stackrel{8}{ \pm} \\
\dot{ \pm}\end{array}$ & $\begin{array}{l}\infty \\
0 \\
b \\
y\end{array}$ & 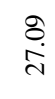 & $\begin{array}{l}\infty \\
\substack{\infty \\
\infty}\end{array}$ \\
\hline 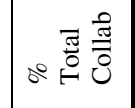 & E & 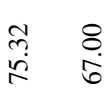 & $\begin{array}{l}\infty \\
\infty \\
\infty \\
\infty\end{array}$ & בี & $\vec{\infty}$ & 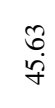 & 壳 \\
\hline 을 & तี่ & 总 & $\stackrel{\infty}{\stackrel{\sim}{\pi}}$ & $\underset{\substack{\infty \\
\stackrel{\infty}{\infty}}}{\infty}$ & $\underset{i}{i}$ & 誉 & $\stackrel{\circ}{\circ}$ \\
\hline 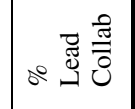 & 密 & $\begin{array}{cc}\stackrel{\infty}{d} & \stackrel{\infty}{\leftrightarrows} \\
\end{array}$ & 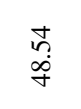 & 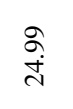 & 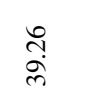 & तू & $\overrightarrow{\rho_{0}}$ \\
\hline$\therefore$ & 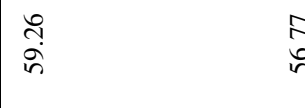 & 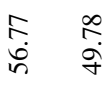 & $\frac{9}{9}$ & 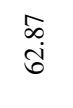 & $\stackrel{8}{0}$ & $\underset{\infty}{\infty}$ & 竎 \\
\hline 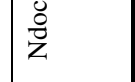 & f & તે ત્તે & $\stackrel{\infty}{\sim}$ & ลี & 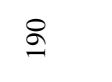 & $\stackrel{\infty}{\subseteq}$ & $\cong$ \\
\hline 童 & 肴 & 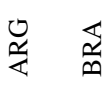 & 交 & $\overrightarrow{8}$ & $\stackrel{\mathbb{x}}{\underline{m}}$ & sै & 吕 \\
\hline 童 & 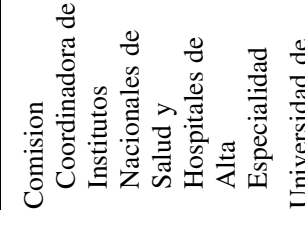 & 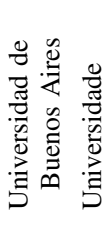 & & & & & 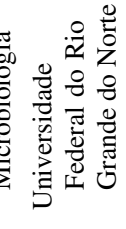 \\
\hline
\end{tabular}




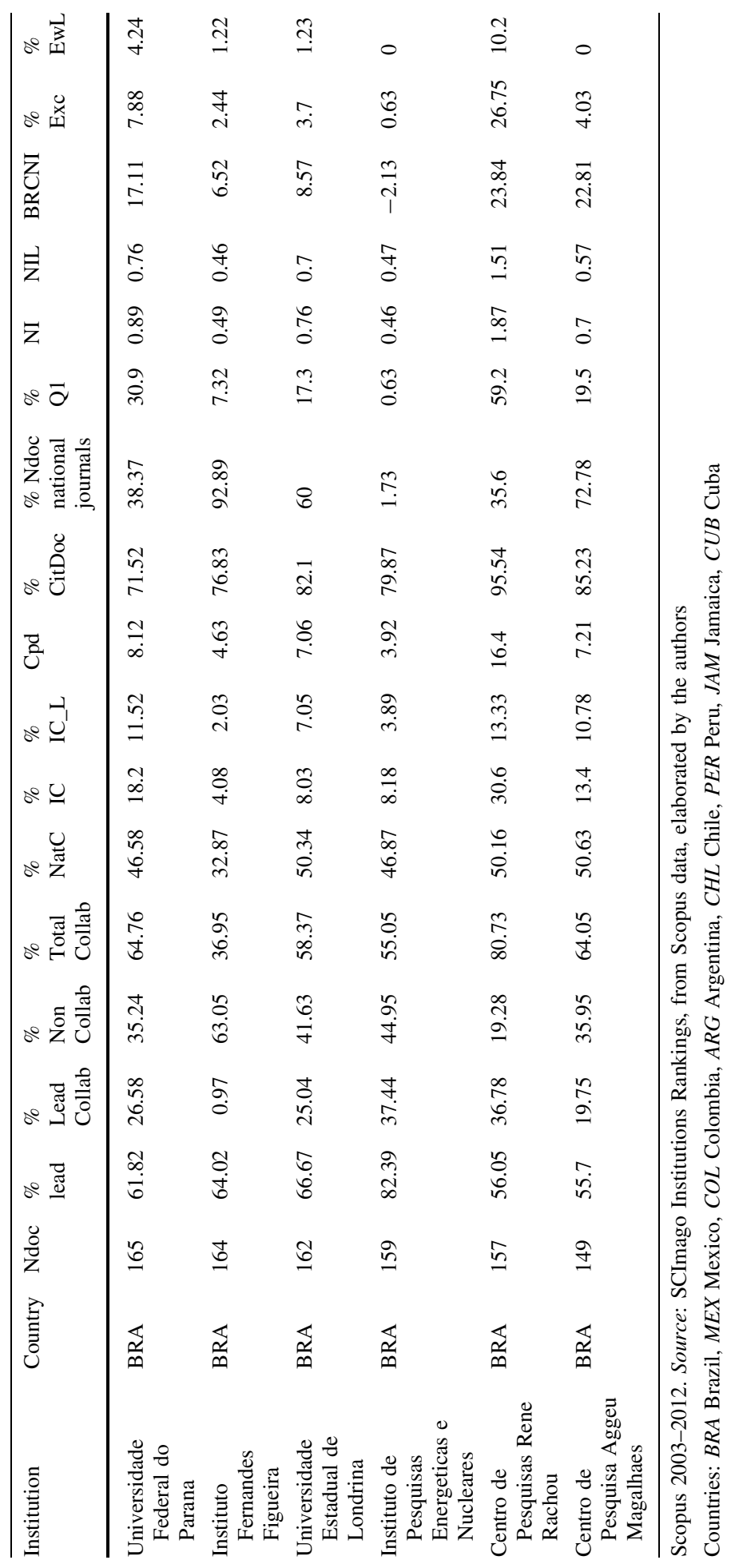


percentage of papers published in national journals, low percentage of international collaboration, a low proportion of cited documents and of citations per document, low normalized impact, high leadership, and non-existent output of excellence. Certain Latin American institutions surpassing the average normalized impact also managed to lead over $50 \%$ of the output of excellence.

A closer look at volume shows Universidade de Sao Paulo, Fundacao Oswaldo Cruz. and Escola Nacional de Saude Publica Sergio Arouca to lead the output ranking. The Instituto Nacional de Salud Pública of Mexico also makes a substantial contribution. More than the half of Latin American institutions showed over $25 \%$ of their output in the first quartile, except Cuban institutions. As seen for Cuba, Latin America also shows disparity between the percentage of coauthored papers and international collaboration. The institutions with the highest percentage of domestic collaboration (more than $60 \%$ of output), both in total and leading output are the Ministerio da Saude (BRA), Consejo Nacional de Investigaciones Científicas y Técnicas (ARG) and Comisión Coordinadora de Institutos Nacionales de Salud y Hospitales de Alta Especialidad (MEX). In general the rates of international collaboration are relatively low, though each case is different. One reason is that nearly $70 \%$ of the institutions are Brazilian, a country having a low percentage of international collaboration, probably due to its vast size, which means a greater number of institutions and resources, as in the case of the United States (Wagner et al. 2015), and also to publishing habits (Leta et al. 2013). On the other hand, it is remarkable that the Universidad Peruana Cayetano Heredia (PER) and the University of the West Indies (JAM) obtain such good results, with international collaboration the norm rather than the exception (Moya-Anegón et al. 2014). The leadership in collaboration is concentrated among the institutions just mentioned, together with Universidade Federal do Ceara (BRA) and Instituto Nacional de Salud Pública (MEX). Those having the highest concentration of leadership in non-collaborative papers are the Instituto Fernandes Figueira (even surpassing the rates of Cuba's INHEM), followed by the Pontificia Universidad Católica de Chile, Universidade Federal do Rio Grande do Norte and the Escola Nacional de Saude Publica Sergio Arouca. Some of these institutions are also characterized by a very high level of publication in national journals with very low impact.

In terms of visibility, quality and excellence, one institution of reference is Brazil's Centro de Pesquisas Rene Rachou — it has the greatest international impact, $95 \%$ of its document receiving citations, along with a mean $16.4 \mathrm{cpd}$. Moreover, the impact of its total output is $87 \%$ above the world average, its leading output over $51 \%$, its rate of excellence is the highest, at $26.75 \%$, and within this set of output of excellence, they flaunt a leadership output index that reaches $10 \%$ while maintaining a high leadership of over $56 \%$ of its contributions (13.3\% international and $57 \%$ domestic).

Also deserving mention is the Universidade Federal de Pelotas, with its $8.63 \%$ excellence with leadership, impact of total and leading output (31 and $29 \%$ respectively over world average) and high values in the rest of the performance indicators. Likewise above the average world impact in their total and leading production are: Instituto Oswaldo Cruz (BRA) and Universidad Peruana Cayetano Heredia (PER), both close to the mean world average of impact in their leading output and showing the highest benefit rate among the most autonomous institutions; Consejo Nacional de Investigaciones Científicas y Técnicas (ARG) has a high level of excellence and excellence with leadership, Universidad de Buenos Aires (ARG) obtains more impact in its leading output, and the Universidade Federal de Minas Gerais (BRA) is closer to the mean average in leading production. Also remarkable are the results of Instituto Nacional de Salud Pública (MEX), the fourth institution in volume of output, demonstrating high leadership in domestic and 
international collaboration, although the rate of excellence with leadership and normalized impact with leadership are far from the world mean. Finally, the institutions with the highest benefit rate in collaboration are INHEM (CUB), Universidad de Antioquia (COL), Instituto Mexicano del Seguro Social (MEX), and Pontificia Universidad Católica de Chile (CHL).

These findings can be adopted as a point of reference to compare the scientific performance of Cuban institutions with other ones in Latin America. The Escola Nacional de Saude Publica Sergio Arouca (BRA) and the Instituto Nacional de Salud Publica (MEX) have profiles similar to that of the ENSAP, yet their volume of production is much greater, the citations per document received respectively around 10 and 7, and over $80 \%$ of their documents are cited, in contrast to the ENSAP citation figure of just $13 \%$. In terms of impact, the Mexican institution attains the worldwide average in total output but receives $30 \%$ less citation than the world mean in its leading output.The top Brazilian institution remains 28 and $39 \%$ below these worldwide values (as opposed to ENSAP, $93 \%$ under the world average). These two institutions of reference had work published in the highly cited output, unlike ENSAP.

\section{Discussion and conclusions}

Almost all the Cuban institutions publishing more than 10 documents in the category of Public Health have a greater level of specialization than the world average. This high degree of specialization has been documented previously (Arencibia-Jorge et al. 2012); moreover, the Cuban institutions that publish the most are also the ones with the highest level of specialization in Public Health (INHEM, ENSAP and IPK).

The analysis of the contribution by institutions reveals an uneven distribution of scientific capacities. The most productive institutions are the ones intrinsically related to public health, e.g. INHEM (first) and ENSAP (third), presenting articles in Cuban journals on Hygiene, Epidemiology and Public Health.

ENSAP is broadly recognized in the region due to its master and doctoral programs (ENSAP 2015). It has a staff of international prestige and excellent performance in teaching and services. Nevertheless, their reputation as a training center is not matched by the results of their research activity. Most of ENSAP's scientific output appears in the Cuban journals dedicated to Higher Medical Education, Public Health, and Integral General Medicine (Sarduy Domínguez et al. 2014). Its output in foreign journals-implying collaboration with other institutions and/or the English language - does not reflect the international dimensions and development of these academic institutions. The ENSAP has indicators of yield that are much lower than other institutions with similar profiles (e.g. Escola Nacional de Saude Publica Sergio Arouca or Instituto Nacional de Salud Publica). Although the indicators of the INHEM are more optimistic than those of ENSAP, they likewise falter in the sense that they do not live up to their potential. The pattern contrasts with the fact that these institutions offer master and doctor degrees related with Public Health, with specialized research outlets. This situation of low indexes of publication in Public Health related with academic programs is true not only of Cuba. It is also characteristic, for example, of Turkey (Sipahi et al. 2012).

IPK looms as the national reference for Public Health research, not only because it takes second place in the volume of output, but also because it attained the highest indicators of quality and internationalization (that is, collaboration plus publication in English in Cuba). 
Other authors have revealed that the results of research by the IPK determine the patterns and specialized production of the national institutes on the whole, and condition the productivity of the authors (Vega Almeida et al. 2007). Also deserving mention is their pattern of scientific communication, different from the rest of the National Health Systems in terms of its objectives, quality, visibility and international impact, output that tends to be published in foreign journals (Cañedo Andalia et al. 2014). The institutional policy of IPK encourages publishing articles in English and in high impact journals, while fomenting the scientific culture of the researchers; domestic journals are also used to communicate the high level results of its research activities. However, when compared to other Latin American institutions, its performance shows room for improvement.

The former ISCM-H, now known as the Universidad de Ciencias Médicas de La Habana, is the largest academic institution of Cuba. It takes in all the medical schools of Havana, and makes an important contribution to Public Health, although its output is hardly noticed by the international community. Even its domestic recognition is limited. In turn, the University of Havana, a generalized academic center that does not belong to the National Health System, demonstrates its versatility in research by contributing over $5 \%$ of the total in Public Health.

The fact that UH and ISCM-H are the most productive institutions of Cuba is a finding reported previously (Arencibia Jorge et al. 2013a, b). At the regional level there exist similar institutions of a general nature, most notably in Brazil, with high quotas of scientific output in Public Health and more favorable indicators of performance. Three examples would be the Universidade de Sao Paulo, Universidade Federal de Minas Gerais, and Universidade Federal do Rio de Janeiro. A close look at Brazilian scientific production, in general and in the case of Public Health, reveals a very positive scenario, with an important increase in the number of postgraduate courses, teachers, and students (Barros 2006). Postgraduate programs in Brazil are under strong pressure from a national scientific evaluation system that sets goals to publish in high Impact Factor journals. But at the Latin American level the end effects of this important trend are hardly discerned, as most institutions do not have such programs. This makes it difficult to draw meaningful conclusions from broad comparisons, a limitation to be explored in future analyses.

Meanwhile, HCQ-HA is a hospital of national reference in Cuba. Although its scope of activity is fundamentally clinical medicine, the Scopus data indicate that it also contributes to the area of Public Health. The impact of this institution is negligible, which contrasts with the considerable leadership it represents regarding the percentage of documents cited, demonstrated in an analysis of inter-sectorial relations for the period 2003-2007 (Arencibia et al. 2013a, b).

Cubás National Health Institutes wield substantial weight in research and output in the health sector, and are held up as the highest institutions of the MINSAP dedicated to research, teaching and medical attention at the tertiary level. The diffusion of the research findings by publication in national journals and international ones is seen to be one of their priorities (Vega Almeida et al. 2007). In the realm of Public Health, especially with regard to international journals, their performance is weak, however. Bearing in mind that the main causes of mortality in Cuba are malignant tumors and heart disease (Ministerio de Salud Pública 2013), one might have expected a greater protagonism of institutions such as the INOR and ICCC in populational studies related with these diseases. The former stands out due to its greater dependence on collaboration to obtain some visibility, and the latter due to a total absence of visibility, despite production completely published in national collaboration. Increasing the volume of production and degree of impact in a balanced way would be a sound strategy for these institutions to follow, a means of elevating the prestige 
of their publication to the same level as Cuba's real advances in Public Health. It would also be a way to attract the collaborative participation of the international community, thus enhancing the repercussions of Cubás scientific output and, in the end analysis, improving the health of the Cuban population.

Very interestingly, among the most productive Latin American institutions there are none specializing in Epidemiology, Tropical Medicine, Cardiology or Oncology; rather, the predominant research institutes and universities are of a generalized nature and focus.

Both at the national and at the institutional level, a vast volume of output has been associated with a greater impact of citation. In other words, the concentration of research in a single institution is positively related with better performance (Moed et al. 2011). Yet this association between the indicators of quantity and quality was not observed among the Cuban institutions studied here. Despite their public character-there are no private health institutions in Cuba-we detect a serious lack of consonance between the volume of output and the impact of this output. Generally speaking, public institutions are the main producers of knowledge in developing nations. In Brazil, for instance, the recent growth spurt of science has meant a change in profile and in publishing dynamics; still, the indicators based on citation point to a less spectacular increase (Glänzel 2000). Similarly, there is no linear correlation between the degree of specialization and its impact on citation per document in Brazil (Moed 2005).

Concerning publication in the most cited journals, one might expect that around $25 \%$ of the documents from a reputed institution would appear in journals of the first quartile (the average of Latin America publications in Q1 is $24.3 \%$ in the case of Public Health). More than the half of the Latin American institutions accomplish this (Table 4); worldwide, $45 \%$ of output is published in journals pertaining to this top quartile (Table 1). Bearing in mind that the output observed should be comparable to the expected output (Bornmann et al. 2014a), it can be said that no Cuban institutions studied lived up to such expectations. A better strategy is clearly needed to heighten the visibility, impact and quality of the scientific activity of these institutions. Namely, they should strive to publish in prestigious journals, which would give them the chance to land more work in the set of most cited papers while increasing their collaborative research efforts. At the same time, it would help alleviate a major problem that becomes evident through Cubás publication patterns-a high level of endogamy. The prevalent trend in Cuba is one of high leadership, but fundamentally owing to publication in national journals, accompanied by low rates of collaboration and scarce publication in English, all of which could have a very negative effect on high performance in terms of publication (Chinchilla-Rodríguez et al. 2015c).

The normalized impact and the percentage of excellence are widely held to be two of the most important bibliometric indicators (Bornmann and Moya Anegón 2014). We found a group of institutions that could be held up as the regional reference, since they surpass the worldwide level of impact in its total and leading production and they place $10 \%$ or more of their articles in the set of highly cited (excellent) publications. These are: Centro de Pesquisas Rene Rachou, Universidade Federal de Pelotas, Instituto Oswaldo Cruz, Universidad de Buenos Aires, Universidade Federal de Minas Gerais, Consejo Nacional de Investigaciones Científicas y Técnicas (Argentina), and Universidad Peruana Cayetano Heredia. None of the Cuban institutions reaches the average international level in this sense (Table 4).

At the regional level, $92 \%$ of the most productive institutions led over half of the publications. Around $40 \%$ of the institutions were the leaders of over $50 \%$ of the output of excellence, and in many of them there was a correspondence between leadership in total output and leadership in output of excellence. 
Notwithstanding, the indicator of leadership shows considerable differences among the institutions studied here, which may have to do with their objectives or competence in the research arena. At any rate, these high levels of leadership cannot always be considered positive for an institution when it is mainly derived from non-collaborative papers. High values of leadership are more valuable for collaborative papers, and especially for the internationally-coauthored ones. Because leadership means merit when it entails domestic or international collaboration, greater scientific impact could be expected. Scientific merit would similarly pertain to the top-cited papers at the global level (excellence with leadership), regardless of the number of institutions coauthoring the paper. Considering the low impact of Cuban publications, high leadership may therefore be interpreted as isolation from the scientific community network and underperformance. Among the most productive Latin American institutions (but to a lesser degree than in Cuba) we also observed a major collaborative dependency in the scientific performance by the Universidad de Antioquia (COL), Instituto Mexicano del Seguro Social (MEX) and the Pontifica Universidad Católica de Chile (CHL). In contrast, the most autonomous and scientifically developed institutions, taking into account the role of national or international leadership in normalized citation are: Universidad de Buenos Aires (ARG), Universidade Federal de Pelotas (BRA), Consejo Nacional de Investigaciones Científicas y Técnicas (ARG), Instituto Oswaldo Cruz (BRA) and the Centro de Pesquisas Rene Rachou (BRA). Furthermore, certain Brazilian centers have not yet reached the world average of normalized citation, but show potential in terms of visibility through their leading production, such as Instituto de Pesquisas Energeticas e Nucleares, Univerisdade Federal do Rio Grande do Norte and Univerisdade do Estado do Rio de Janeiro.

To correct the high level of leadership in non-collaboration seen for Cuban institutions, it would be necessary to motivate and optimize researchers, providing incentives through specific institutional and national policies. Also highly recommendable is a reinforcement of national collaboration, which is on the decline in recent years (Zacca-González et al. 2015), aside from international exchange. By stimulating collaboration among hospitals, primary attention centers, and research institutions, doctors and professors would adopt a more active role in research activity and organizations (Arencibia Jorge et al. 2013a, b). The present study corroborates the scientific capacity of a number of Latin American institutions, which generate quality research results and lend opportunities to establish projects of international collaboration. This is particularly true of Brazil-a great number of Cuban doctors work on Brazilian health initiatives. Directives in science and technology could help establish alliances among such institutions. The objective at hand is to increase visibility and the quality of Cuban scientific output in Public Health, so that Cuba will derive more socioeconomic benefits from its research while consolidating an international reputation in the field.

There is a fully developed methodology designed to evaluate the EPHF ${ }^{1}$ in the health system. The figures obtained in this study can be taken as an objective complement to further assess the results of scientific activities. In addition to gauging institutional capacity in a generic way, the results of the present study provide specific data about the most productive institutions in terms of scientific output. Accordingly, we identified a lack of

\footnotetext{
1 The EPHF includes a methodology that allows countries to evaluate their public health capacity through a collective survey. Each indicator has a standard model and a series of measurements that describes in detail the capacities necessary for optimal performance of the function, in terms of structure, processes, and specific outcomes associated with performance. The specific indicators of the EPHF 10 are: development of public health research plans; development of the institutional capacity for research and advisory services and technical support for research at the sub-national public health entities.
} 
alliances entailing research and academic centers, collaborative efforts able to carry out studies that would support decision-making processes by national health authorities at all levels. The scanty use made of research results-that is, scientific output-reveals deficiencies in the innovation behind Public Health practices. This study provides information on which to base policy in the context of the research agenda, such as reinforcing the Public Health infrastructure in terms of human resources and materials, as well as improving practices in communication and diffusion. Through comparative benchmarking at an international level, standards for scientific activity become manifest. The Latin American institutions sharing similar profiles, hence appropriate for collaborative alliances, thereby come to light.

In Cuba and elsewhere there is a largely untapped potential for generating scientific knowledge of high quality. Strategies are needed to deliberately stir up the research capacities of highly specialized institutions, to elevate the quality of Cuban science in the area of Public Health, fundamentally through collaboration. This would give rise to greater visibility and international repercussions, promoting leadership with excellence and leadership in collaboration. The international embargo to which Cuba has been subjected for so many years is at the roots of the scientific isolation that is signaled by our findings. This is not only true of Public Health, but of Cuban scientific activity overall. The past situation meant problems for Cuban researchers aspiring to go abroad, to attend international congresses and similar events, which makes it difficult for these specialists to establish international ties (Chinchilla-Rodríguez et al. 2015a).

The new geo-political scenario, together with improved means of producing and divulging knowledge, will make it easier to foment and fortify networks of collaboration among the most productive institutions in Public Health, in Latin America and on other continents. The strength of the Cuban institutions is their high level of specialization, whereas the international impact, high level of journal endogamy and leadership in collaboration are the weak points to be corrected.

Beyond the scope of this paper, but equally meaningful for a thorough analysis of the state-of-the-art of Latin American research, other important aspects to be explored in future analysis are the role of leadership in scientific excellence, the size of the institutions (the number of researchers, budgetary resources, etc.), type of institution (university, national institute, hospital, governmental), the levels of productivity and the underlying academic, scientific and technological structure on the whole. As mentioned above, one key lies in the national scientific evaluation systems that establish specific goals related to performance and results. This essential yet variable aspect of scientific policy can interfere with large-scale institutional comparisons. Further research is needed to determine the significance of such variables and offer useful information about the effectiveness and accountability of vast systems of knowledge production, so as to enhance the management of institutionalized research initiatives.

Concerning the methodology used, the results of this study provide relevant information regarding the influence of leadership in the institutional scientific performance. While we present the situation of Cuba and Latin American institutions, the methodology described could be applied to other geographic and thematic domains.

Acknowledgments This work was made possible through financing by the scholarship funds for international mobility between Andalusian and IberoAmerican Universities and the SCImago Group. The authors appreciate the comments of the reviewers, which served to improve the quality and clarity of the manuscript, as well as the support in translating/editing of the manuscript by Jean Sanders. 


\section{References}

Abramo, G., Cicero, T., \& D’Angelo, C. (2013). National peer-review research assessment exercises for the hard sciences can be a complete waste of money: The Italian case. Scientometrics, 95(1), 311-324.

Aguillo, I., Bar-Ilan, J., Levene, M., \& Ortega, J. (2010). Comparing university rankings. Scientometrics, 85, 243-256.

Arencibia Jorge, R., Carrillo Calvet, H., Corera Álvarez, E., Chinchilla Rodríguez, Z., \& de Moya Anegón, F. (2013a). La investigación científica en las universidades cubanas y su caracterización a partir del ranking de instituciones de SCImago. Revista Universidad de La Habana, 276, 163-192.

Arencibia Jorge, R., Corera Álvarez, E., Chinchilla Rodríguez, Z., \& de Moya Anegón, F. (2013b). Intersectoral relationships, scientific output and national policies for research development: A case study on Cuba 2003-2007. Revista Cubana de Información en Ciencias de la Salud, 24(3), 243-254.

Arencibia-Jorge, R., Vega-Almeida, R., Chinchilla-Rodríguez, Z., Corera-Álvarez, E., \& Moya-Anegón, F. (2012). Patrones de especialización de la investigación cubana en salud. Revista Cubana de Salud Pública, 38(supl. 5), 734-747.

Barros, A. J. D. (2006). Scientific output in the collective health area: Journal profile and evaluation by Capes. Revista de Saúde Pública, 40(spe), 43-49.

Bornmann, L. (2011). Scientific peer review. Annual Review of Information Science and Technology, 45, 199-245.

Bornmann, L. (2013). The problem of citation impact assessments for recent publication years in institutional evaluations. Journal of Informetrics, 7, 722-729.

Bornmann, L., de Moya Anegón, F., \& Leydesdorff, L. (2010). Do scientific advancements lean on the shoulders of giants? A bibliometric investigation of the Ortega hypothesis. PLoS One, 5(10), e13327.

Bornmann, L., de Moya Anegón, F., \& Leydesdorff, L. (2012). The new excellence indicator in the world report of the SCImago Institutions Rankings 2011. Journal of Informetrics, 6(2), 333-335.

Bornmann, L., \& Moya Anegón, F. (2014). What proportion of excellent papers makes an institution one of the best worldwide? Specifying thresholds for the interpretation of the results of the SCImago Institutions Ranking and the Leiden Ranking. Journal of the Association for Information Science and Technology, 65(4), 732-736.

Bornmann, L., \& Mutz, R. (2011). Further steps towards an ideal method of measuring citation performance: The avoidance of citation (ratio) averages infield-normalization. Journal of Informetrics, 5(1), 228-230.

Bornmann, L., Stefaner, M., Moya Anegón, F., \& Mutz, R. (2014a). Ranking and mapping of universities and research-focused institutions worldwide based on highly-cited papers. A visualisation of results from multi-level models. Online Information Review, 38(1), 43-58.

Bornmann, L., Stefaner, M., Moya Anegón, F., \& Mutz, R. (2014b). What is the effect of country-specific characteristics on the research performance of scientific institutions? Using multi-level statistical models to rank and map universities and research-focused institutions worldwide. Journal of Informetrics, 8, 581-593.

Calero-Medina, C., López-Illesca, C., Visser, M. S., \& Moed, H. F. (2008). Important factors when interpreting bibliometric rankings of world universities: An example in the field of oncology. Research Evaluation, 17(1), 71-81.

Cañedo Andalia, R., Rodríguez Labrada, R., Dorta Contreras, A. J., \& Velázquez Pérez, L. (2014). Producción científica en salud de Cuba registrada en PubMed en el periodo 2010-2012. Revista Cubana de Información en Ciencias de la Salud, 25(2), 157-171.

Centre for Science and Technology Studies (CWTS). (2014). Leiden ranking. www.leidenranking.com. Accessed 25 July 2014.

CHE Centre for Higher Education. (2014). U-Multirank. www.u-multirank.eu. Accessed 25 July 2014.

Chinchilla-Rodríguez, Z., Arencibia-Jorge, R., Moya-Anegón, F., \& Corera-Álvarez, E. (2015a). Some patterns of Cuban scientific publication in Scopus: The current situation and challenges. Scientometrics, 103(3), 779-794.

Chinchilla-Rodríguez, Z., Miguel, S., \& Moya-Anegón, F. (2015b). What factors are affecting the visibility of Argentinean publications in human and social sciences in Scopus? Some evidences beyond the geographic realm of the research. Scientometrics, 102(1), 789-810.

Chinchilla-Rodríguez, Z., Zacca-González, G., Vargas-Quesada, B., \& Moya-Anegón, F. (2015c). Latinoamerican scientific output in Public Health: Combined analysis of bibliometric, socioeconomic and health indicators. Scientometrics, 102(1), 609-628.

Escuela Nacional de Salud Pública (ENSAP). (2015). www.ensap.sld.cu. Accessed 7 August 2015.

Glänzel, W. (2000). Science in Scandinavia: A bibliometric approach. Scientometrics, 48, 121-150. 
Glänzel, W., Thijs, B., Schubert, A., \& Debackere, K. (2009). Subfield-specific normalized relative indicators and a new generation of relational charts: Methodological foundations illustrated on the assessment of institutional research performance. Scientometrics, 78(1), 165-188.

Guerrero, V. P., Olmeda-Gomez, C., \& Moya-Anegón, F. (2013). Quantifying the benefits of international scientific collaboration. Journal of the Association for Information Science and Technology, 64(2), 392-404.

Hazelkorn, E. (2013). How rankings are reshaping higher education. In V. Climent, F. Michavila, \& M. Ripolles (Eds.), Los rankings univeritarios: Mitos y realidades. Madrid: Ed. Tecnos.

Hendrix, D. (2008). An analysis of bibliometric indicators, National Institutes of Health funding, and faculty size at Association of American Medical Colleges medical schools, 1997-2007. Journal of Medical Library Association, 96(4), 324-334.

Huang, M. H. (2012). Exploring the h-index at the institutional level. A practical application in world university rankings. Online Information Review, 36(4), 534-547.

Huang, M. H., Chang, H. W., \& Chen, D. Z. (2006). Research evaluation of research-oriented universities in Taiwan from 1993 to 2003. Scientometrics, 67(3), 419-435.

Institute of Higher Education, Shanghai Jiao Tong University. (2013). Academic ranking of world universities (ARWU). http://www.shanghairanking.com. Accessed 25 July 2014.

Leta, J., Thijs, B., \& Glänzel, W. (2013). A macro-level study of science in Brazil: Seven years later. Encontros Biblio: Revista Eletrônica de Biblioteconomia e Ciência da Informaçao, 18(36), 51-66.

Ministerio de Salud Pública. (2013). Anuario Estadístico de Salud. La Habana: Dirección Nacional de Registros Médicos y Estadísticas.

Moed, H. F. (2005). Citation analysis in research evaluation. Dordrecht: Springer.

Moed, H. F., Moya-Anegón, F., López-Illescas, C., \& Visser, M. (2011). Is concentration of university research associated with better research performance? Journal of Informetrics, 5(4), 649-658.

Moya-Anegón, F., Chinchilla-Rodríguez, Z., Bustos-González, A., Corera-Álvarez, E., López-Illescas, C., \& Vargas-Quesada, B. (2014). Principales indicadores bibliométricos de la actividad científica de la Pontificia Universidad Católica del Perú. Lima: Pontificia Universidad Católica del Perú.

Moya-Anegón, F., Guerrero-Bote, V. P., Bornmann, L., \& Moed, H. F. (2013). The research guarantors of scientific papers and the output counting: A promising new approach. Scientometrics, 97, 421-434.

Pan American Health Organization/World Health Organization (PAHO/WHO). (2002). Public health in the Americas: Conceptual renewal, performance assessment, and bases for action. Washington, DC: PAHO/WHO.

Rehn, C., Kronman, U., \& Wadskog, D. (2007). Bibliometric indicators: Definitions and usage at Karolinska Institutet version 1.0. Stockholm: Karolinska Institutet University Library.

Rodríguez-Navarro, A. (2012). Counting highly cited papers for university research assessment: Conceptual and technical Issues. PLoS One, 7(10), e47210.

Sarduy Domínguez, Y., Llanusa Ruiz, S. B., Urra González, P., \& Antelo Cordovés, J. M. (2014). Caracterización de la producción científica de la Escuela Nacional de Salud Pública referenciada en la base de datos Scopus, 2006-2012. Educación Médica Superior, 28(2). http://www.ems.sld.cu/index.php/ ems/article/view/201.

SCImago Institutions Rankings. (2014). http://www.scimagoir.com. Accessed 4 August 2014.

Sipahi, H., Durusoy, R., Ergin, I., Hassoy, H., Davas, A., \& Karababa, A. O. (2012). Publication rates of public health theses in international and national peer-review journals in Turkey. Iranian Journal of Public Health, 41(9), 31-35.

Vega Almeida, R. L., Arencibia Jorge, R., \& Araújo Ruiz, J. A. (2007). Producción científica de los institutos de salud de Cuba en el Web of Science en el periodo 2000-2004. Acimed, 16(3). http://bvs. sld.cu/revistas/aci/vol16_3_07/aci03907.htm.

Vieira, E. S., \& Gomes, J. (2010). A research impact indicator for institutions. Journal of Informetrics, 4, 581-590.

Wagner, C. S., Park, H. W., \& Leydesdorff, L. (2015). The continuing growth of global cooperation networks in research: A conundrum for national governments. PLoS One, 10(7), e0131816. doi:10. 1371/journal.pone.0131816.

Zacca-González, G., Chinchilla-Rodríguez, Z., Vargas-Quesada, B., \& de Moya-Anegón, F. (2015). Patrones de comunicación e impacto de la producción científica cubana en Salud Pública. Revista Cubana de Salud Pública, 41(2), 200-216.

Zacca-González, G., Chinchilla-Rodríguez, Z., Vargas-Quesada, B., \& Moya-Anegón, F. (2014a). Bibliometric analysis of Latin America's regional scientific output in Public Health through SCImago Journal and Country Rank. BMC Public Health, 14 (http://www.biomedcentral.com/1471-2458/14/632 DOI: 10.1186/1471-2458-14-632), 632.

Zacca-González, G., Vargas-Quesada, B., Chinchilla-Rodríguez, Z., \& Moya-Anegón, F. (2014b). Producción científica cubana en Medicina y Salud Pública. Scopus 2003-2011. Transinformação, 26(3), 281-293. 